\title{
The concurrence of atmospheric rivers and explosive cyclogenesis in the North Atlantic and North Pacific basins
}

\author{
Jorge Eiras-Barca ${ }^{1}$, Alexandre M. Ramos ${ }^{2}$, Joaquim G. Pinto ${ }^{3}$, Ricardo M. Trigo ${ }^{2}$, \\ Margarida L. R. Liberato ${ }^{2,4}$, and Gonzalo Miguez-Macho ${ }^{1}$ \\ ${ }^{1}$ Non-Linear Physics Group, Universidade de Santiago de Compostela, Galicia, Spain \\ ${ }^{2}$ Instituto Dom Luiz (IDL), Faculdade de Ciências, Universidade de Lisboa, 1749-016 Lisboa, Portugal \\ ${ }^{3}$ Institute for Meteorology and Climate Research (IMK-TRO), \\ Karlsruhe Institute of Technology (KIT), Karlsruhe, Germany \\ ${ }^{4}$ Escola de Ciências e Tecnologia, Universidade de Trás-os-Montes e Alto Douro, Vila Real, Portugal
}

Correspondence: Alexandre M. Ramos (amramos@fc.ul.pt) and Jorge Eiras-Barca (jorge.eiras@usc.es)

Received: 18 August 2017 - Discussion started: 22 August 2017

Revised: 27 November 2017 - Accepted: 4 December 2017 - Published: 22 January 2018

\begin{abstract}
The explosive cyclogenesis of extratropical cyclones and the occurrence of atmospheric rivers are characteristic features of a baroclinic atmosphere, and are both closely related to extreme hydrometeorological events in the mid-latitudes, particularly on coastal areas on the western side of the continents. The potential role of atmospheric rivers in the explosive cyclone deepening has been previously analysed for selected case studies, but a general assessment from the climatological perspective is still missing. Using ERA-Interim reanalysis data for 1979-2011, we analyse the concurrence of atmospheric rivers and explosive cyclogenesis over the North Atlantic and North Pacific basins for the extended winter months (ONDJFM). Atmospheric rivers are identified for almost $80 \%$ of explosive deepening cyclones. For non-explosive cyclones, atmospheric rivers are found only in roughly $40 \%$ of the cases. The analysis of the time evolution of the high values of water vapour flux associated with the atmospheric river during the cyclone development phase leads us to hypothesize that the identified relationship is the fingerprint of a mechanism that raises the odds of an explosive cyclogenesis occurrence and not merely a statistical relationship. These new insights on the relationship between explosive cyclones and atmospheric rivers may be helpful to a better understanding of the associated high-impact weather events.
\end{abstract}

\section{Introduction}

Intense extratropical cyclones are one of the major natural threats in mid-latitudes and are often responsible for large socioeconomic impacts (Munich Re, 2015). Their impacts include strong winds, heavy precipitation, and in some cases storm surges (e.g. Lamb, 1991) In particular, cases associated with explosive cyclogenesis (Sanders and Gyakum, 1980; pressure decrease larger than $24 \mathrm{hPa}$ in $24 \mathrm{~h}$ at $60^{\circ} \mathrm{N}$, or equivalent) are associated with particularly large impacts and often with low predictability (e.g. Wernli et al., 2002; Fink et al., 2009). Such systems are often referred to in the literature as "bombs". According to Shapiro et al. (1998), explosive cyclogenesis result from different mechanisms that include upper-level cyclonic vorticity advection, low-level warm air advection, and latent heat release. This may be supported by upper-tropospheric Rossby wave breaking, which constrains and intensifies the upper-level jet stream and thus contributes to intense cyclone developments (e.g. Hanley and Caballero, 2012; Gómara et al., 2014). According to Aubert (1957), the latent heating influence is significant not only in the pressure distribution but also in the vertical motion field. In particular, Aubert (1957) states that this mechanism lowers the heights of isobaric surfaces in the lower troposphere, 
and raises them in the upper. In agreement, Tsou et al. (1987) found that even for cases with strong vorticity advection and the differential thermal advection, latent heat release is still primary cause of the pressure falling below $900 \mathrm{hPa}$ during the period of most abundant precipitation. The release of latent heat contributes to increase the storm's available potential energy, deepening the cyclone while decreasing the horizontal scale of the region of ascent particularly in maritime cyclones (e.g. Emanuel, 1987; Snyder and Lindzen, 1991; Davis, 1992).

Several studies have confirmed the occurrence of a maximum of latent and sensible heat availability in the lower troposphere near the warm sector of the cyclone and documented the contribution of moist diabatic processes such as latent heat release by cloud condensation processes to the intensification of extratropical cyclones (Pinto et al., 2009; Liberato et al., 2012; Ludwig et al., 2014). However, the relative contribution of diabatic processes to the cyclone deepening may differ considerably from case to case. For example, Fink et al. (2012) showed for selected explosive cyclogenesis cases that while diabatic processes played a key role for storms such as Xynthia and Klaus, other storms are largely baroclinic driven (e.g. Kyrill and Martin). These results have recently been extended by Pirret et al. (2017), who provided evidence that baroclinic processes generally dominate the majority of storms. On the other hand, the contributions from diabatic processes varies strongly from cases to case, and are only dominant for 10 out of 58 cases. The role of the diabatic contribution is strongly related to the period of time that a storm remains equatorward side of the jet, where warm, moist air is present.

The higher moisture availability in the North Pacific and North Atlantic basins are controlled by so-called atmospheric rivers (ARs; e.g. Newell and Zhu, 1994; Zhu and Newell, 1998; Bao et al., 2006; Ralph and Dettinger, 2011; Gimeno et al., 2016). ARs are relatively narrow (on average $500 \mathrm{~km}$ ) corridors of enhanced water vapour (WV) transport in the lower troposphere that can extend for thousands of kilometres. According to the American Meteorological Society glossary ARs are "a long, narrow, and transient corridor of strong horizontal water vapour transport that is typically associated with a low-level jet stream ahead of the cold front of an extratropical cyclone". The definition also states that the water vapour in ARs is supplied by sourced of tropical and/or extratropical origin (e.g. Ramos et al.2016a; Eiras et al., 2017) and that ARs can lead to heavy precipitation whenever these systems are forced upward - either by mountains or by ascent in the warm conveyor belt. Horizontal water vapour transport in the midlatitudes occurs primarily in atmospheric rivers and is focused in the lower troposphere. The importance of ARs in extreme precipitation events and floods has been analysed in detail for the west coast of the USA (particularly for California) over the last decade (e.g. Ralph et al., 2004; Neiman et al., 2008; Dettinger et al., 2011). Similar conclusions have been reached for Europe (e.g. Malguzzi et al., 2006; Lavers et al., 2012; Liberato et al., 2012; Ramos et al., 2015; Eiras-Barca et al., 2016; Brands et al., 2017) and other regions of the world (e.g. Viale and Nuñez, 2011; Mahoney et al., 2016; Blamey et al., 2018).

Given the role of latent heat release in the development of explosive cyclogenesis, this suggests that explosive cyclogenesis in the mid-latitudes may be influenced by the presence of an AR. Additionally, the release of sensible heat in the vicinity of the cyclone will enhance the convective instability of the AR. Previous studies showed for selected case studies that explosive development can indeed be driven by the presence of an AR (Zhu and Newell, 1994; Ferreira et al., 2016). For example, Ferreira et al. (2016) have provided evidence on the role of ARs over the western and central (sub)tropical Atlantic towards cyclone development, which converged into the cyclogenesis region and then moved along with the storm towards Europe. However, to the best of our knowledge, no ample assessments analysing the role of ARs in the explosive deepening have been performed from the climatological perspective. The main objective of this study is to provide a comprehensive evaluation on the role of the ARs in the explosive deepening of North Atlantic and North Pacific extratropical cyclones between 1979 and 2011 for the extended winter months (ONDJFM), focusing on the spatial concurrence and the timing of both features.

The manuscript is organized as follows: Sect. 2 describes the data and methods, while the results are presented in Sect. 3; finally, the conclusions are given and discussed in Sect. 4.

\section{Data and methods}

We use ECMWF ERA-Interim Reanalysis (Dee et al., 2011) between 1979 and 2011 for our study. For the cyclone detecting and tracking methodology (see Sect. 2.1), 6-hourly instantaneous $1000 \mathrm{hPa}$ geopotential height fields at a resolution of $0.75^{\circ} \times 0.75^{\circ}$ are considered. For the detecting and tracking of the ARs' structures (see Sect. 2.2), we used moisture and wind values at multiple vertical pressure levels to compute the integrated water vapour column (IWV) and the vertically integrated horizontal water vapour transport (IVT) at the same resolution.

\subsection{Cyclone detecting and tracking methodology}

We have applied an automatic procedure to identify and track extratropical cyclones (Trigo, 2006). This particular cyclone detecting and tracking algorithm was first developed for the Mediterranean region (Trigo et al., 1999, 2002), later extended to a larger Euro-Atlantic region (Trigo, 2006) and finally generalized for both hemispheres (e.g. Neu et al., 2013). The scheme is applied to the ERA-Interim geopotential height at $1000 \mathrm{hPa}$ (Z1000) fields. Cyclones are identified and tracked at a 6-hourly basis at the spatial resolution available of $0.75^{\circ} \times 0.75^{\circ}$ for the entire Northern Hemi- 
sphere. Results from this method compare well with other similar methods (Neu et al., 2013). Storms with minimum central pressure higher than $1010 \mathrm{hPa}$ over their entire life cycle and lasting less than $24 \mathrm{~h}$ are discarded from the subsequent analysis. For each cyclone, the maximum deepening rate $\Delta P$ per cyclone track is determined by the maximum pressure drop at the centre of the cyclone on the basis of all the $6 \mathrm{~h}$ successive time steps $((P(t-6)-P(t))$ in its life cycle. The maximum deepening point (MDP) corresponds to the point $P(t)$ and was computed for each cyclone in order to analyse the influence of the ARs on its maximum deepening rate. We choose the maximum deepening point rather than the minimum pressure point of the cyclone because it is in this time frame of the cyclone development that an influence from AR may be expected. By choosing the MDP, we guarantee that the potential trigger effect for its maximum deepening occurred at the same time or just prior to it. From this database, the sub-set of explosive cyclogenesis (EC) is selected for further analysis. Following Bergeron (1954) and the generalization by Sanders and Gyakum (1980), explosive cyclones are defined as cyclones with deepening rates (NDR) exceeding $24 \mathrm{hPa}$ in $24 \mathrm{~h}$ for a reference latitude of $60^{\circ} \mathrm{N}$, where NDR is defined as NDR $=\left(\Delta p_{\mathrm{c}} \sin 60\right) /(24|\sin \varphi|)$, where $\Delta p_{\mathrm{c}}$ is the change in central pressure in $24 \mathrm{~h}$ and $\varphi$ is the latitude of the cyclone core at MDP. All remaining cyclones are included in the sub-set non-explosive cyclones (NEC). In addition, for the AR analysis, all the cyclones below $25^{\circ} \mathrm{N}$ were filtered in order to avoid tropical storms and hurricanes in our analysis.

Two wide domains over both ocean basins have been selected: for the Atlantic domains latitudes between $25^{\circ} \mathrm{N}$ and $65^{\circ} \mathrm{N}$ and longitudes between $80^{\circ} \mathrm{W}$ and $10^{\circ} \mathrm{E}$ are considered, while for the Pacific domain longitudes are between $120^{\circ} \mathrm{E}$ and $105^{\circ} \mathrm{W}$. Regarding the extended winter months, for the North Atlantic Basin, a total of 8048 cyclones were detected, from which 733 were classified as EC $(9.1 \%$ of the cases). Regarding the Pacific domain, a total of $12005 \mathrm{cy}-$ clones were identified, in which 1115 were classified as EC ( $9.3 \%$ of the cases).

Figure 1 shows the spatial distribution of the positions where EC reached their minimum core pressure during lifetime. Depicted are the number of events per extended winter (ONDJFM) season per $5^{\circ} \times 5^{\circ}$ grid box, normalized to the corresponding area for $50^{\circ} \mathrm{N}$ (about $200 \times 10^{3} \mathrm{~km}^{2}$ ). The density maps of cyclone positions provide a good overview of the distribution of explosive cyclones in both basins. While for the Atlantic storm track a clear SW-NE orientation is found, reaching values of 0.8 events per extended winter near the American continent, over the Pacific Basin the storm track is more zonal and reached values of 0.9 events per extended winter over the central-western basin.
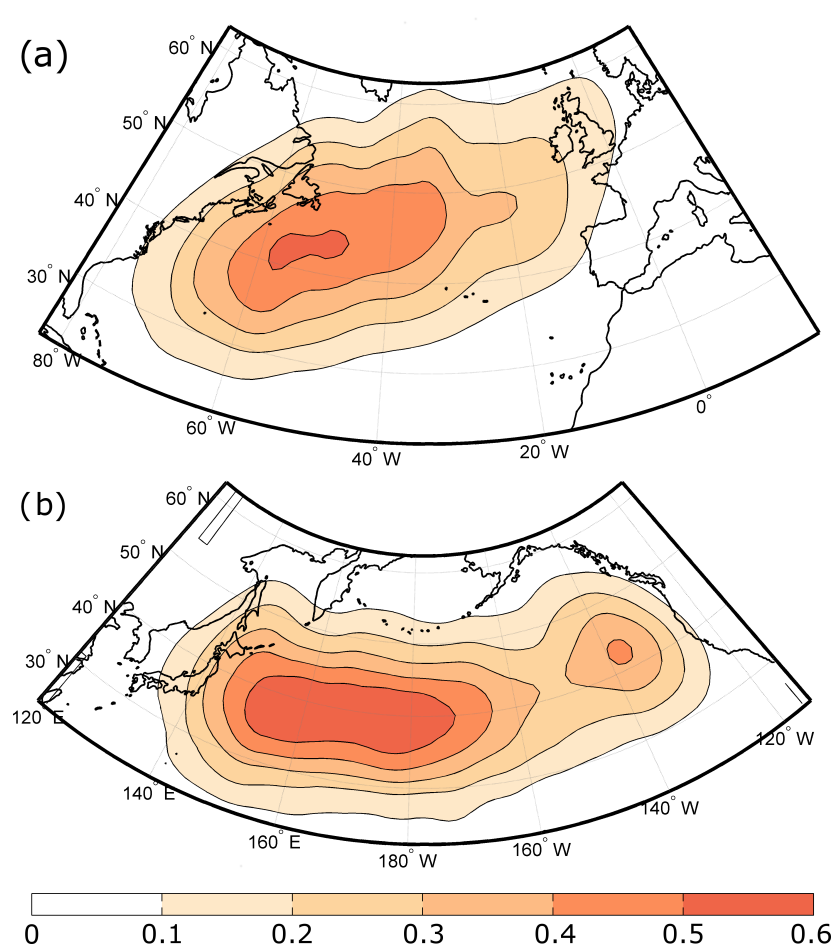

Figure 1. Spatial distribution of the location where explosive cyclogenesis reach their minimum core pressure for (a) Atlantic Ocean and (b) Pacific Ocean. Contours correspond to the average number of events per extended winter (ONDJFM) season, detected per $5^{\circ} \times 5^{\circ}$ area normalized for $50^{\circ} \mathrm{N}$. The spatial distribution was smoothed with a $5^{\circ}$ averaging radius.

\subsection{Atmospheric river detection}

There are several methodologies to detect ARs, which can broadly be divided into two groups considering the nature of the main dataset used, either satellite data or reanalysis data (Gimeno et al., 2014). For methods using satellite data, the different approaches consider the IWV, obtained mainly from the SSM/I sensor (e.g. Ralph et al., 2004; Guan et al., 2010; Ralph and Dettinger, 2011). For methods based on reanalysis data, we focus on the IVT (e.g. Zhu and Newell, 1998; Lavers et al., 2013) or the method of Eiras-Barca et al. (2016), which uses a combination of IWV and IVT from ERA-Interim reanalysis. An overview of the different methods to identify ARs can be found in Gimeno et al. (2014). Given the different approaches to identify them, and in order to estimate the sensitivity of the results for the choice of identification method, we employ two different methods to identify them.

The first method is an adaptation of the Eiras-Barca et al. (2016) approach (hereafter EIRAS2016), which uses not only IWV but also the IVT to identify ARs. For each cyclone, the location and timing of the MDP (see Sect. 2.1) along the cyclone track is used as a starting point. In $6 \mathrm{~h}$ time steps and for $\mathrm{a} \pm 36 \mathrm{~h}$ window frame around the MDP, we search within a radius of $1500 \mathrm{~km}$ surrounding the centre of 


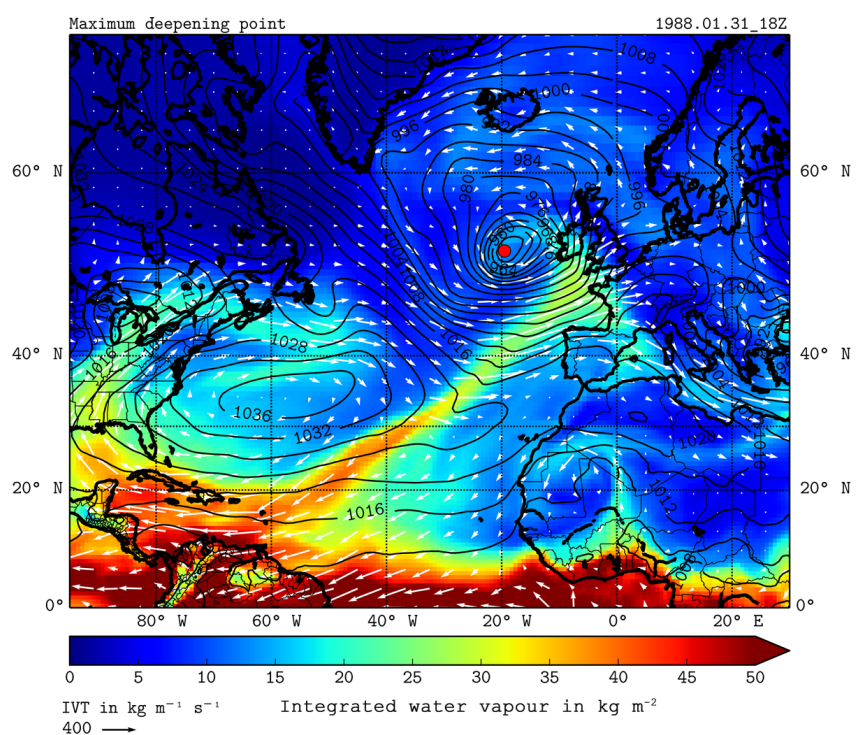

(a)

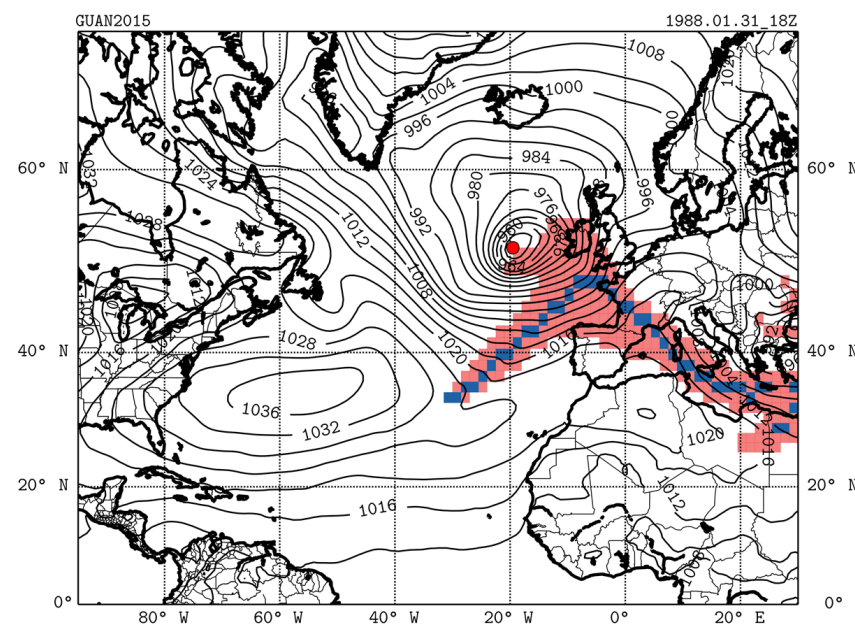

(b)

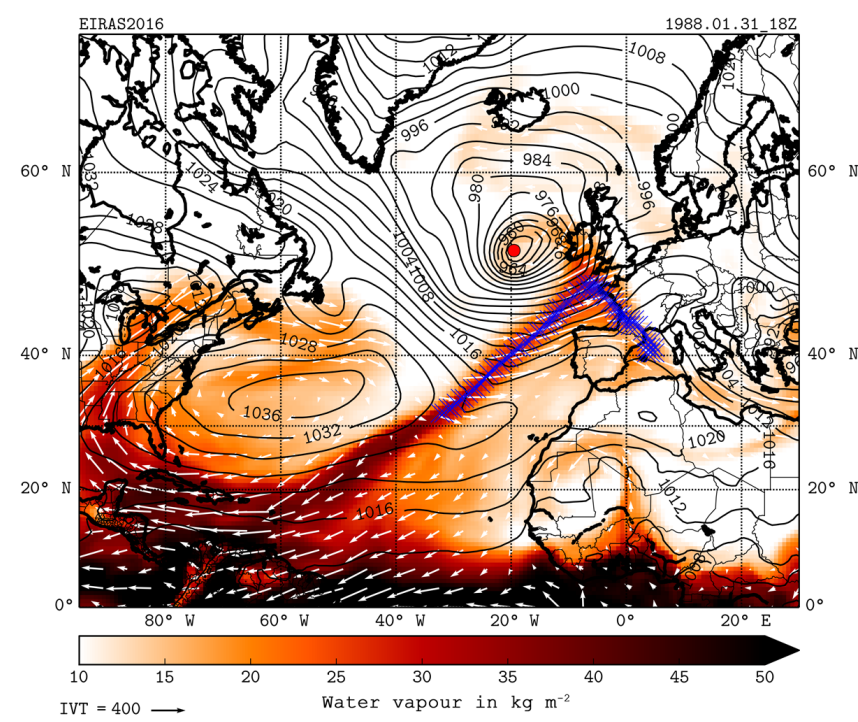

(c)

Figure 2. Example of a well-defined atmospheric river associated with an explosive cyclone development making landfall over the British Isles on 31 January 1988, 18:00 UTC. Mean sea level pressure field (hPa) is indicated as black isolines in all panels. (a) Total integrated column of water vapour (IWV, colours, $\mathrm{kg} \mathrm{m}^{-2}$ ) and integrated vapour transport (IVT, arrows, $\mathrm{kg} \mathrm{m}^{-1} \mathrm{~s}^{-1}$ ). (b) Shape region (red) and central axis of the atmospheric river (blue) for the GUAN2015 algorithm. (c) As (a) but showing only IWV values above $10 \mathrm{~kg} \mathrm{~m}^{-2}$; the blue crosses highlight the central axis of the atmospheric river detected by the EIRAS2016 algorithm. In addition the location of the MDP is highlighted with a red dot.

the cyclone location at that time for the maximum values of IWV which are above the local 85th monthly percentile. If a grid point is selected, the neighbouring grid points are also investigated. This procedure continues as long as the threshold conditions are met, building 2-D features. A feature must have a minimum extension of $2000 \mathrm{~km}$ to be considered an AR. The search radius of $1500 \mathrm{~km}$ has been selected to take the shape and geometry of ARs and cyclones into account. While smaller radii of search may be in some cases insuffi- cient to detect ARs in the vicinity of large cyclones, larger radii of search could detect other ARs which are unrelated to the analysed cyclone, leading to a false detection.

The second ARs detection scheme was developed by Guan and Waliser (2015) (hereafter GUAN2015) using also the ERA-Interim Reanalysis. The database used here (shape boundary and axis of the ARs) was provided by the authors. For this method, there is no need for a reference starting point to search for the ARs. Instead, the method isolates 
contiguous regions of the world of enhanced IVT exceeding a certain IVT threshold ( $>85$ th percentile or $100 \mathrm{~kg} \mathrm{~m}^{-1} \mathrm{~s}^{-1}$, whichever is greater). Each of these regions will be subsequently analysed for the geometry requirement of length $>2000 \mathrm{~km}$, length/width ratio $>2$ and other considerations indicative of ARs conditions (see Guan and Waliser, 2015). Both algorithms operate using variable spatial and time dependent thresholds. The assignment of the cyclones to the GUAN2015 ARs is performed in an identical way as for EIRAS2016 to warrant comparability. Both methodologies were applied to both EC and NEC sub-sets in order to quantify the role of the ARs for the development of explosive cyclones.

\subsection{Example of detection}

A good example of a well-defined AR can be found in Fig. 2. The selected case corresponds to an explosive cyclone where the MDP occurred on the 31 January 1988 at 18:00 UTC west of Ireland (approximately at latitude $51^{\circ} \mathrm{N}$ and longitude $20^{\circ} \mathrm{W}$, red dot in Fig. 2b and c). The overall IWV pattern is clearly compatible with the presence of an AR-like structure located in the North Atlantic Ocean, showing an extensive region with high IWV values extending from the Caribbean to the British Isles (Fig. 2a). In this case, the IVT preferred direction along the high IWV region is directed from SW to $\mathrm{NE}$ between the sub-tropics and the cyclone centre. However it seems that for these particular time steps the supply of water vapour from the tropics is cut off by the presence of the high-pressure system located east of Florida which steers the IVT direction from the sub-tropics to the tropics. This preliminary visual assessment of the presence of an ARs is confirmed using the GUAN2015 algorithm in Fig. 2b, where the two highlighted regions that are distinguished corresponding to the "shape" region (reddish), which is the region where the AR can exist, and the blue line depicts the central axis of maximum intensity of the AR detected by the GUAN2015 method. Similarly, in Fig. 2c the results for the EIRAS2016, for the same case, are shown; here the detection of the central axis of the AR (blue crosses) event illustrated in Fig. 2a is shown.

\section{Results}

Both AR detection methodologies were applied to the entire cyclone database. The obtained information was used to estimate the relevance of the ARs in the occurrence of explosive cyclogenesis and compare it with the corresponding NEC results. First, we analyse the samples of cyclones in each sub-set in terms of the evolution of core pressure over time. Supplement Fig. S1 depicts the distributions of core pressure values from $-36 \mathrm{~h}$ until $+36 \mathrm{~h}$ from MDP, for both the North Atlantic and North Pacific basins and for EC and NEC. Please note that the number of cyclones included in the statistics changes over time (Supplement Table S1), as not all systems have the same lifetime. EC systems typically deepen around $30 \mathrm{hPa}$ during their lifetime and attain a minimum core pressure around MDP +6 or $+12 \mathrm{~h}$. Afterwards, occlusion advances and the systems fill in and consequently core pressure slowly increases with time. On the other hand, the pressure changes for NEC is typically much smaller (around $10 \mathrm{hPa}$ ) and the minimum peak intensity is difficult to identify since the core pressure more or less is stable after MDP. The increase in core pressure over time after MDP $+6 \mathrm{~h}$ is thus not identifiable for NEC systems.

Regarding the concurrence of these events with ARs, Fig. 3 shows the ratios of observed coincidence between the $\mathrm{EC}$ and the presence of an AR within a $1500 \mathrm{~km}$ radius of the cyclone for the North Atlantic (Fig. 3a) and for the North Pacific (Fig. 3b), including the variance as the error bars for each MDP. The first prominent result is high ratios of coincidence between ARs for EC, peaking between 70 and $80 \%$ for time lags MDP-6h to MDP+6. When focusing on the North Atlantic region (Fig. 3a), the maximum $(\sim 78 \%)$ is found for the MDP+6h using the GUAN2016, while using the EIRAS2016 the maximum $(\sim 74 \%)$ is at the MDP timing. Likewise, for the Pacific Basin (Fig. 3b) the ratios of coincidence with the ARs reach a maximum of $78 \%$ when using the GUAN2016 on the MDP-6, while when using the EIRAS2016 its maximum $(\sim 72 \%)$ is found at the MDP. The results for the EC are in line with those found by Zhu and Newell (1994) and Ferreira et al. (2016) for a few selected case studies, where ARs were identified near the cyclones during an explosive cyclogenesis. In addition, we show here that the temporal coincidence between the ARs and explosive deepening of the cyclone takes place primarily between $-6 \mathrm{~h}$ and $+6 \mathrm{~h}$ around the MDP. Our results support the findings by Pirret et al. (2017), as the presence of the ARs will enhance the warm advection ahead of the cyclone core during the development phase.

For NEC, the concurrence of ARs during the development phase is considerably smaller. For the North Atlantic Region (Fig. 3a), the values for NEC range from about $55 \%$ with the GUAN2015 and close to $45 \%$ with the EIRAS2016 method. For the North Pacific Basin (Fig. 3b), results for the NEC are similar (but lower ratios) to those found for the North Atlantic Basin, ranging from approximately $46 \%$ in the GUAN2015 to nearly $42 \%$ when using EIRAS2016. In addition, for the NEC, there is apparently an increase in the ratio of coincidence between the position of the NEC and the presence of the ARs from $-36 \mathrm{~h}$ to $+36 \mathrm{~h}$. This can be associated with the convergence of moisture along the frontal system of the cyclones (Dacre et al., 2015) along with tropical moisture export episodes (Knippertz and Wernli (2010) which can potentiate the formation of an AR in the latter stages of the NEC.

The conclusions attained with both methodologies are very similar. While a clear peak is identified close to the MDP for EC, for NEC a stable relationship with the ARs is identified in both methodologies with almost no changes in 


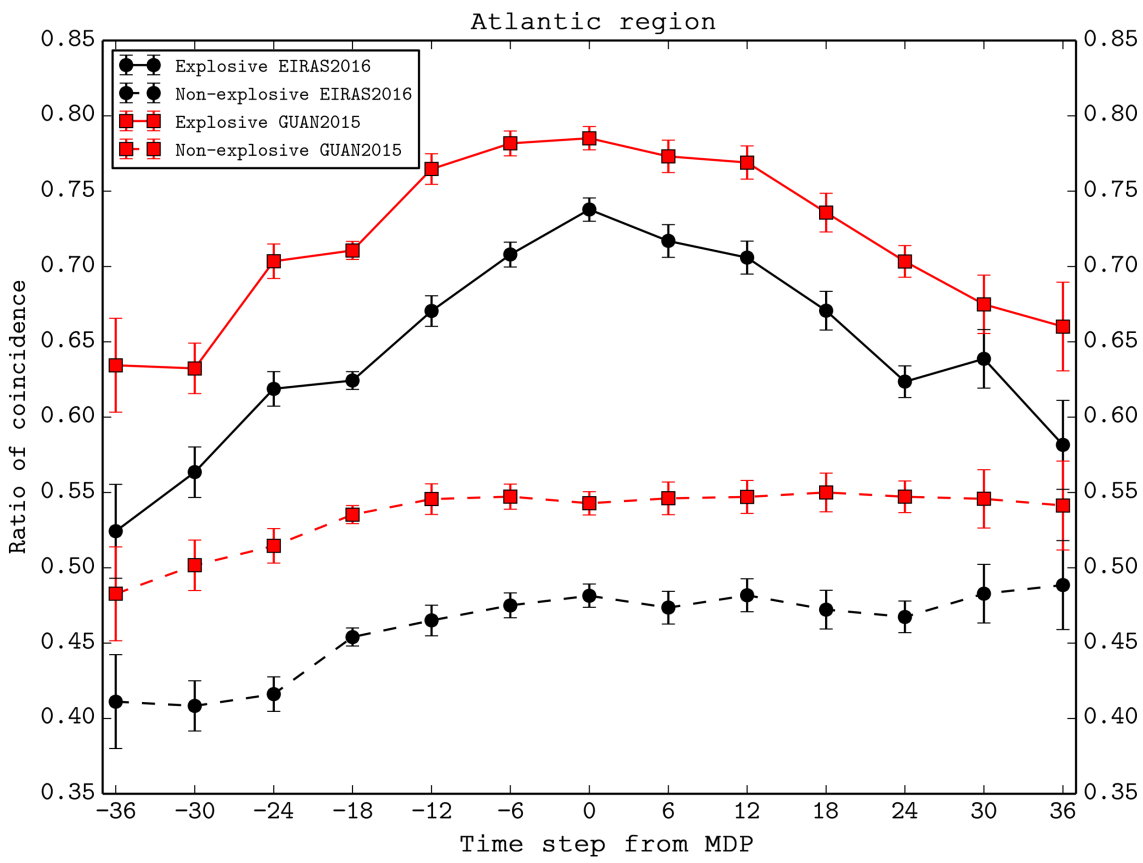

(a)

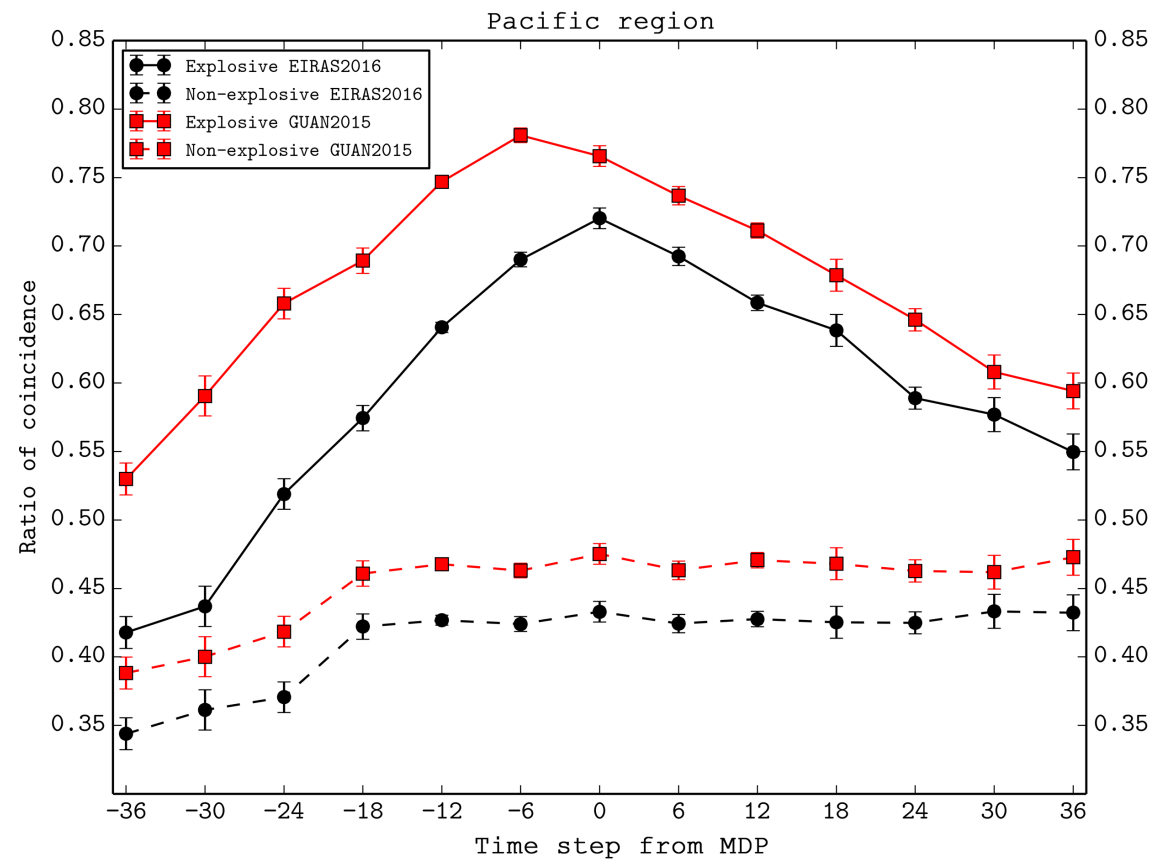

(b)

Figure 3. (a) Ratio of coincidence between the position of the cyclones for the North Atlantic Basin and the presence of an Atmospheric River in a $1500 \mathrm{~km}$ radius. The maximum deepening point (MDP) is fixed as time reference and results are shown for $\pm 36 \mathrm{~h}$ of the MDP. Red lines correspond to the GUAN2015 method and black lines to the EIRAS2016 method. Solid lines refer to explosive cyclogenesis (EC) and dotted lines refer to non-explosive events (NEC). (b) As (a) but for the North Pacific Basin. In addition the variance of each time step is also shown.

the ratio of coincidence when analysing the different $6 \mathrm{~h}$ time frames. However, the ratio of coincidence is always higher when using the GUAN2015.
Regarding the spatial distribution of the EC-AR coincidences, no conclusions can be achieved based on our results. Supplement Fig. S2 shows the position of the EC during the MDP if the AR coincidence was detected (red dots) and if 

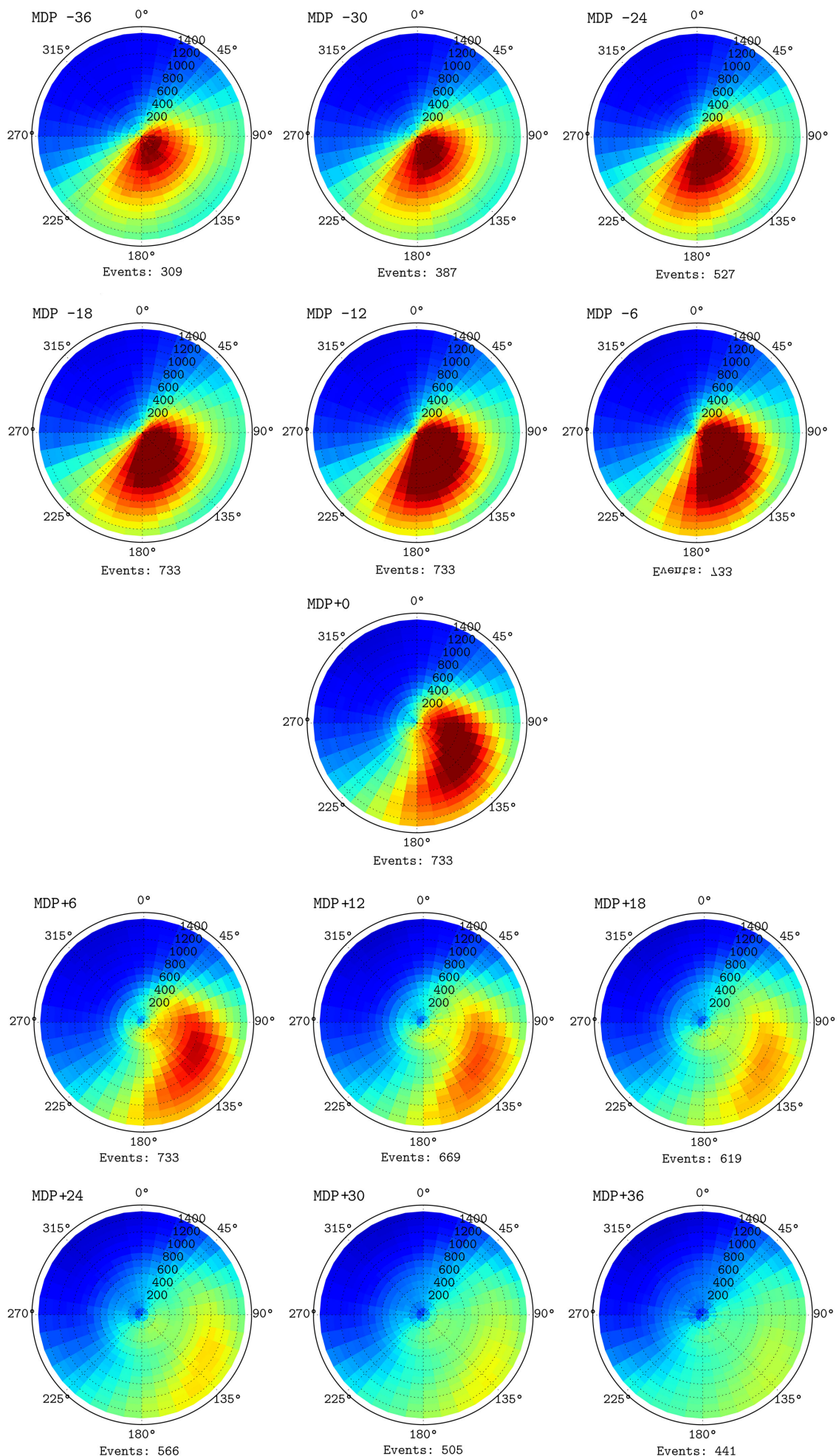

Zenith in $\mathrm{km}$, azimuth in degrees

IVT $\left(\mathrm{kg} \mathrm{m}^{-1} \mathrm{~s}^{-1}\right)$

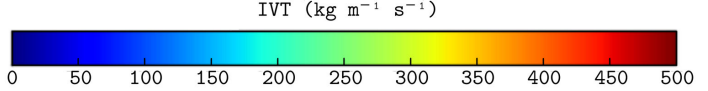

Figure 4. Composite of the integrated vapour transport (IVT, colours, $\mathrm{kg} \mathrm{m}^{-1} \mathrm{~s}^{-1}$ ) within a $1500 \mathrm{~km}$ radius around the cyclone core of an explosive cyclogenesis (EC) cyclone for the North Atlantic Basin for the period 1979-2011. The maximum deepening point (MDP) is fixed as time reference and results are shown for $\pm 36 \mathrm{~h}$ of the MDP. 

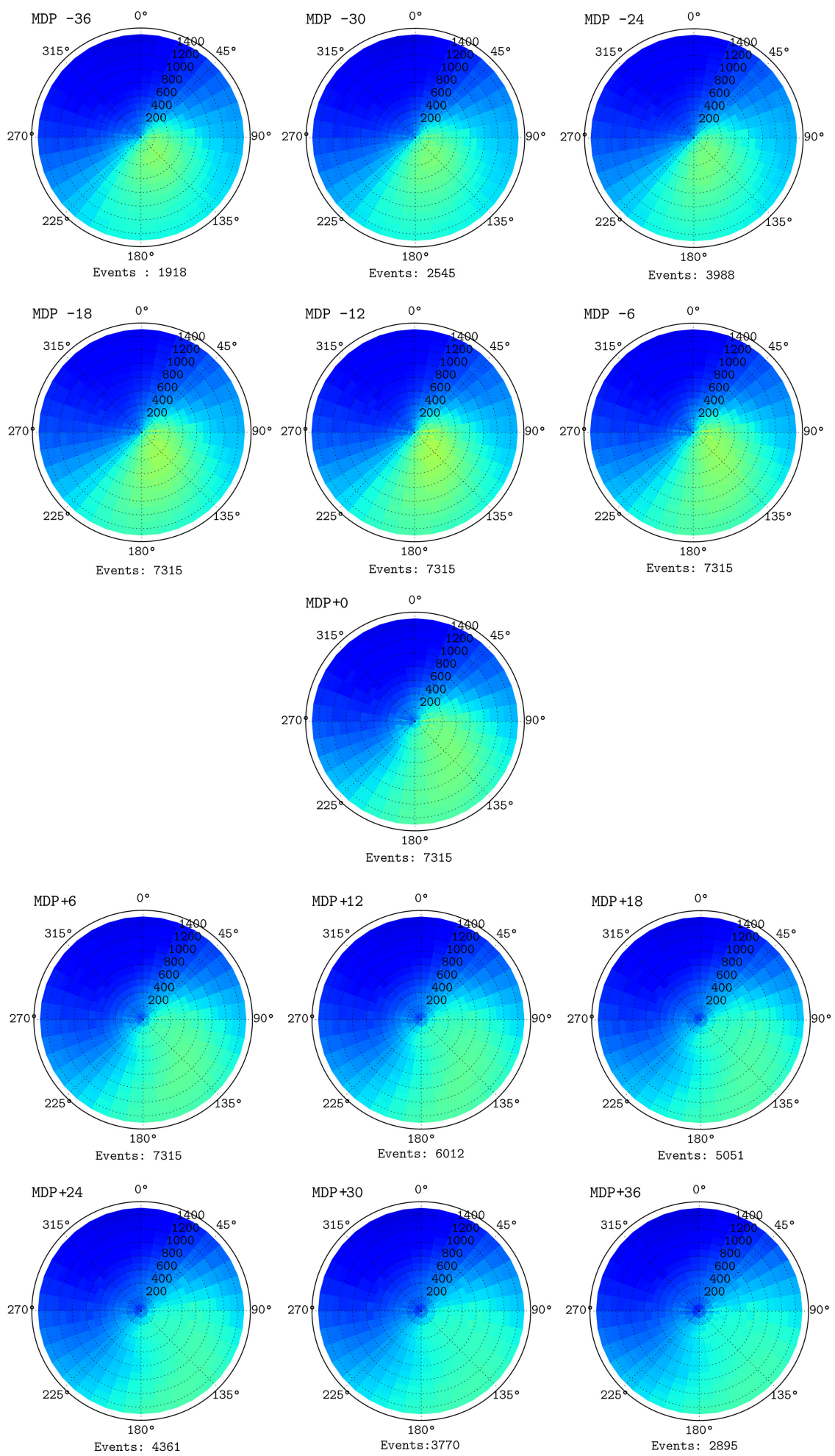

Zenith in $\mathrm{km}$, azimuth in degrees

IVT $\left(\mathrm{kg} \mathrm{m}^{-1} \mathrm{~s}^{-1}\right)$

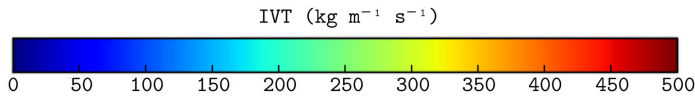

Figure 5. Same as Fig. 4 but for non-explosive cyclogenesis (NEC). 
it was not (black crosses). At first sight, the coincidences and non-coincidences of explosive cyclogenesis with ARs seem to be roughly equally distributed throughout the Atlantic and Pacific domains. However, on the downstream end of the storm tracks, cases with concurrent AR seem to dominate (e.g. over the British Isles). Still, no general conclusions can be made on a possible relation on the location of explosive cyclogenesis and concurrence (or non-concurrence) with anomalous moisture flux near the cyclones.

In order to analyse the flux of moisture near the cyclones within $\pm 36 \mathrm{~h}$ of the MDP, spatial composites of the IVT within radius of $1500 \mathrm{~km}$ from the cyclone core were computed for each time step, for the EC and for the NEC and for both domains. Figure 4 shows the composites of the IVT in the surroundings of EC between $-36 \mathrm{~h}$ and $+36 \mathrm{~h}$ from the MDP at $6 \mathrm{~h}$ time steps for the North Atlantic, while Fig. 5 shows the same fields but for NEC. One key difference between both figures is noticeable differences in the IVT fields, which implies the presence of intense IVT values akin to ARlike structures in explosive cyclogenesis when compared to the NEC events.

Since ARs are commonly spatially associated with the warm sector of the cyclone, the evolution of the IVT fields throughout the $36 \mathrm{~h}$ time frame adjacent to the MDP frame depicts the general frontal evolution over the cyclogenesis event. Note that the AR is already quite prominent at MDP$36 \mathrm{~h}$ for EC events, and its position slowly rotates around the cyclone core MDP with slightly increasing intensities. Also noteworthy is the fact that, after the MDP point, not only does the AR strongly weaken but its central axis also tends to be detached from the cyclone with increasing time, corresponding to the detachment from the warm sector from the cyclone core at later stages of cyclone development (occlusion is initiated). This conclusion is in line with that obtained by Zhu and Newell (1994) for a much smaller number of cases. While the EC samples are dominated by systems associated with an AR (Fig. 3), this is not always the case. In order to evaluate this in more detail, we analysed additional composites by separating the EC cyclones in two categories, namely EC with AR (EC-AR) and without AR (EC-nonAR; Supplement Fig. S3). As expected, results show that there is a considerable difference in the composites between EC$\mathrm{AR}$ and EC-nonAR, with high values of IVT identified for EC-AR and considerable lower values for EC-nonAR. The figures for EC-nonAR are more similar to NEC systems (not shown).

Supplement Figs. S4 and S5 show the composites for EC and NEC events but for the North Pacific domain. No meaningful differences can be observed between the North Atlantic and the North Pacific basins, and thus the conclusions are the same for the North Atlantic. The results suggest the importance of latent heat released when the cyclones encounter the ARs, leading to intense condensation process, thus providing an important source of energy when the cy- clone is in its deepening phase (e.g. Danard, 1964; Bullock and Jonhson, 1971; Whitaker and Davis, 1994).

The results presented in this section have revealed two main new insights. First, the highest ratio of the present of the ARs in the vicinity of EC is found within $\pm 6 \mathrm{~h}$ of the MDP. Second, it is apparent for EC events that the AR is located very close to the cyclone centre prior to MDP, while the AR becomes detached from the EC core once the cyclone stops deepening. As a result, we confirm the hypothesis that the presence of an AR raises the odds of an explosive cyclogenesis occurrence and is thus not only merely a statistical relationship as suggested by Ferreira et al. (2016) for three modelled EC case studies.

\section{Conclusions}

We investigated the importance of ARs in the development of explosive cyclogenesis on both North Atlantic and North Pacific basins using two different algorithms for AR identification. With this aim, the concurrence of the presence of AR in the vicinity of developing cyclones was quantified over different time lags. The main results are summarized in the following:

- ARs are present very frequently within the vicinity of cyclones undergoing EC, reaching maximum values close to $80 \%$ near the MDP $( \pm 6 \mathrm{~h})$ for both domains. The concurrence of ARs with NEC is $42-46 \%$ for NEC.

- While slightly different results are obtained with the two AR methodologies, the results are consistent, both in terms of the general numbers and the time evolution of concurrences between AR and cyclogenesis over time. While a clear peak is found for EC, a steady relationship is identified for NEC. The obtained conclusions are thus robust and largely independent of the detection AR algorithm used.

- Since ARs are commonly associated with the warm sector of the cyclone, the evolution of the IVT fields throughout the $\pm 36 \mathrm{~h}$ frame surrounding the MDP point depicts the general frontal evolution over the cyclogenesis event. Prior to the MDP, high values of IVT are already present at $-36 \mathrm{~h}$, with the maximum values of IVT appearing around the MDP $( \pm 6 \mathrm{~h})$. Afterwards, the IVT values quickly decrease and the central AR axis tends to be detached from the cyclone.

- The analysis of NEC composites reveals much lower values of IVT during development. This is a clear indication of the unusual characteristics of the IVT for EC cases.

The above results strongly indicate that the presence of an AR near the developing cyclone is related to a higher probability of an explosive cyclogenesis occurrence. A detailed 
analysis of the time evolution of the high values of water vapour flux associated with the AR during the cyclone development phase leads us to hypothesize that this fact is a fingerprint of a physical mechanism that raises the odds of an explosive cyclogenesis occurrence and not merely a statistical relationship. Given the previous work of Zhu and Newell (1994) on selected case studies, our analysis allows for a systemization of results from a climatological perspective. This insight can be potentially helpful to a better understanding of the occurrence of high-impact weather associated with both explosive cyclones and atmospheric rivers. A detailed analysis of the changes in terms of cyclone structure and intensity would enable a further step forward towards a better predictability of such extreme events.

Regarding future climate projections, Ramos et al. (2016b) showed that most models from CMIP5 project a coherent increase in IVT values over the North Atlantic Basin and an increase in the number of ARs that hit western Europe by the end of the 21st century, although this is more evident with emissions scenario RCP8.5 than with scenario RCP4.5. Taken together with the new insights of the current paper, such climate change scenarios imply that the probability of intense extratropical explosive cyclones will increase in future decades.

Data availability. No public data are derived from this research.

Supplement. The supplement related to this article is available online at: https://doi.org/10.5194/esd-9-91-2018-supplement.

Author contributions. JEB, AMR, and JGP developed the concept of the paper and wrote the first manuscript draft. JEB performed the data analysis and prepared the figures. MLR provided the cyclone track data. All authors contributed with ideas, interpretation of the results, and manuscript revisions.

Competing interests. The authors declare that they have no conflict of interest.

Special issue statement. This article is part of the special issue "The 8th EGU Leonardo Conference: From evaporation to precipitation: the atmospheric moisture transport". It is a result of the 8th EGU Leonardo Conference, Ourense, Spain, 25-27 October 2016.

Acknowledgements. The ECMWF ERA-Interim reanalysis data were obtained from https://www.ecmwf.int/en/forecasts/datasets/ reanalysis-datasets/era-interim. Jorge Eiras-Barca would like to thank Bin Guan for kindly sharing the ARs detection database. Jorge Eiras-Barca was financially supported by the Spanish government (MINECO) and Xunta de Galicia (CGL2013-45932-R,
GPC2015/014 - ERDF), and contributions by the COST action MP1305 and CRETUS Strategic Partnership (AGRUP2015/02). Alexandre M. Ramos was supported through a postdoctoral grant (SFRH/BPD/84328/2012) from the Portuguese Science Foundation (Fundação para a Ciência e a Tecnologia, FCT). Alexandre M. Ramos and Ricardo M. Trigo were supported by the project IMDROFLOOD - Improving Drought and Flood Early Warning, Forecasting and Mitigation using real-time hydroclimatic indicators (WaterJPI/0004/2014), funded by Fundação para a Ciência e a Tecnologia, Portugal (FCT). Joaquim G. Pinto thanks AXA Research Fund for support. The authors thank Helen Dacre and Vicente Pérez Muñuzuri for helpful discussions. Finally the authors would like to thank Antonio Speranza and two anonymous referees, who helped to improve the final version of the manuscript.

Edited by: Valerio Lucarini

Reviewed by: Antonio Speranza and two anonymous referees

\section{References}

Aubert, E. J.: On the release of latent heat as a factor in large scale atmospheric motions, J. Meteorol., $\quad 14, \quad 527-542, \quad$ https://doi.org/10.1175/15200469(1957)014<0527:OTROLH>2.0.CO;2, 1957.

Bao, J- W., Michelson, S. A., Neiman, P. J., Ralph, F. M., and Wilczak, J. M.: Interpretation of enhanced integrated water vapor bands associated with extratropical cyclones: Their formation and connection to tropical moisture, Mon. Weather Rev., 134, 1063-1080, https://doi.org/10.1175/MWR3123.1, 2006.

Bergeron, T.: The problem of tropical hurricanes, Q. J. Roy. Meteor. Soc., 80, 131-164, https://doi.org/10.1002/qj.49708034402, 1954.

Blamey, R. C., Ramos, A. M., Trigo, R. M., Tomé, R., and Reason, C. J.: The influence of Atmospheric Rivers over the South Atlantic on Winter Rainfall in South Africa, J. Hydrometeor., 19, 127-142, https://doi.org/10.1175/JHM-D-17-0111.1, 2018.

Brands, S., Gutiérrez, J. M., and San-Martín, D.: Twentieth-century atmospheric river activity along the west coasts of Europe and North America: algorithm formulation, reanalysis uncertainty and links to atmospheric circulation patterns, Clim. Dynam., 48, 9-10, https://doi.org/10.1007/s00382-016-3095-6, 2017.

Bullock, B. R. and Johnson, D. R.: The generation of available potential energy by sensible heating in southern ocean cyclones, Q. J. Roy. Meteor. Soc., 98, 495-518, https://doi.org/10.1002/qj.49709841703, 1971.

Dacre, H., Clark, P., Martinez-Alvarado, O., Stringer, M., and Lavers, D.: How do atmospheric rivers form?, B. Am. Meteorol. Soc., 96, 1243-1255, https://doi.org/10.1175/BAMS-D-14$00031.1,2015$.

Danard, M. B.: On the influence of released latent heat on cyclone development, J. Appl. Meteorol., $\quad 3, \quad 27-37, \quad \mathrm{https}$ ///doi.org/10.1175/15200450(1964)003<0027:OTIORL>2.0.CO;2, 1964.

Davis, C. A.: Piecewise potential vorticity inversion, J. Atmos. Sci., 49, 1397-1411, https://doi.org/10.1175/15200469(1992)049<1397:PPVI>2.0.CO;2, 1992.

Dee, D. P., Uppala, S. M., Simmons, A. J., Berrisford, P., Poli, P., Kobayashi, S., Andrae, U., Balmaseda, M. A., Balsamo, G., 
Bauer, P., Bechtold, P., Beljaars, A. C. M., van de Berg, L., Bidlot, J., Bormann, N., Delsol, C., Dragani, R., Fuentes, M., Geer, A. J., Haimberger, L., Healy, S. B., Hersbach, H., Hólm, E. V., Isaksen, L., Kållberg, P., Köhler, M., Matricardi, M., McNally, A. P., Monge-Sanz, B. M., Morcrette, J.-J., Park, B.-K., Peubey, C., de Rosnay, P., Tavolato, C., Thépaut, J.-N., and Vitart, F. : The ERA-Interim reanalysis: configuration and performance of the data assimilation system, Q. J. Roy. Meteor. Soc., 137, 553597, https://doi.org/10.1002/qj.828, 2011.

Dettinger, M., Ralph, F. M., Das, T., Neiman, P. J., and Cayan, D. R.: Atmospheric rivers, floods and the water resources of California, Water, 3, 445-478, https://doi.org/10.1002/qj.828, 2011.

Eiras-Barca, J., Brands, S., and Miguez-Macho, G.: Seasonal variations in North Atlantic atmospheric river activity and associations with anomalous precipitation over the Iberian Atlantic Margin, J. Geophys. Res.-Atmos., 121, 931-948, https://doi.org/10.1002/2015JD023379, 2016.

Eiras-Barca, J., Dominguez, F., Hu, H., Garaboa-Paz, D., and Miguez-Macho, G.: Evaluation of the moisture sources in two extreme landfalling atmospheric river events using an Eulerian WRF tracers tool, Earth Syst. Dynam., 8, 1247-1261, https://doi.org/10.5194/esd-8-1247-2017, 2017.

Emanuel, K. A.: The dependence of hurricane intensity on climate, Nature, 326, 483-85, https://doi.org/10.1063/1.43909, 1987.

Ferreira, J. A., Liberato, M. L. R., Ramos, A. M.: On the relationship between atmospheric water vapour transport and extratropical cyclones development, Phys. Chem. Earth, 94, 56-65, https://doi.org/10.1016/j.pce.2016.01.001, 2016.

Fink, A. H., Brücher, T., Ermert, V., Krüger, A., and Pinto, J. G.: The European storm Kyrill in January 2007: synoptic evolution, meteorological impacts and some considerations with respect to climate change, Nat. Hazards Earth Syst. Sci., 9, 405-423, https://doi.org/10.5194/nhess-9-405-2009, 2009.

Fink, A. H., Pohle, S., Pinto, J. P., and Knippertz, P.: Diagnosing the influence of diabatic processes on the explosive deepening of extratropical cyclones, Geophys. Res. Lett., 39, L07803, https://doi.org/10.1029/2012GL051025, 2012.

Gimeno, L., Nieto, R., Vázquez, M., and Lavers, D. A.: Atmospheric rivers: a mini-review, Front. Earth Sci., 2, 2, https://doi.org/10.3389/feart.2014.00002, 2014.

Gimeno, L., Dominguez, F., Nieto, R., Trigo, R., Drumond, A., Reason, C., Taschetto, A. S., Ramos, A. M., Kumar, R., and Marengo, J.: Major mechanisms of atmospheric moisture transport and their role in extreme precipitation events, Annu. Rev. Env. Resour., 41, 117-141, https://doi.org/10.1146/annurevenviron-110615-085558, 2016.

Gómara, I., Pinto, J. G., Woollings, T., Masato, G., Zurita-Gotor, P., and Rodríguez-Fonseca, B.: Rossby wave-breaking analysis of explosive cyclones in the Euro-Atlantic sector, Q. J. Roy. Meteor. Soc., 140, 738-753, https://doi.org/10.1002/qj.2190, 2014.

Guan, B. and Waliser, D. E.: Detection of atmospheric rivers: evaluation and application of an algorithm for global studies, J. Geophys. Res.-Atmos., 120, 12514-12535, https://doi.org/10.1002/2015JD024257, 2015.

Guan, B., Molotch, N. P., Waliser, D. E., Fetzer, E. J., and Neiman, P. J.: Extreme snowfall events linked to atmospheric rivers and surface air temperature via satellite measurements, Geophys. Res. Lett., 37, L20401, https://doi.org/10.1029/2010GL044696, 2010.
Hanley, J. and Caballero, R.: The role of large-scale atmospheric flow and Rossby wave breaking in the evolution of extreme windstorms over Europe, Geophys. Res. Lett., 39, L21708, https://doi.org/10.1029/2012GL053408, 2012.

Knippertz, P. and Wernli, H.: A Lagrangian climatology of tropical moisture exports to the Northern Hemispheric extratropics, J. Climate, 23, 987-1003, https://doi.org/10.1175/2009JCLI3333.1, 2010.

Lamb, H.: Historic Storms of the North Sea, British Isles and Northwest Europe, Cambridge University Press, Cambridge, 1991.

Lavers, D. A. and Villarini, G.: The nexus between atmospheric rivers and extreme precipitation across Europe, Geophys. Res. Lett., 40, 3259-3264, https://doi.org/10.1002/grl.50636, 2013.

Lavers, D. A., Villarini, G., Allan, R. P., Wood, E. F., and Wade, A. J.: The detection of atmospheric rivers in atmospheric reanalyses and their links to British winter floods and the large-scale climatic circulation, J. Geophys. Res.-Atmos., 117, D20106, https://doi.org/10.1029/2012JD018027, 2012.

Liberato, M. L. R., Ramos, A. M., Trigo, R. M., Trigo, I. F., Durán-Quesada, A. M., Nieto, R., and Gimeno, L.: Moisture sources and large-scale dynamics associated with a flash flood event, in: Lagrangian Modeling of the Atmosphere, edited by: Lin, J., Brunner, D., Gerbig, C., Stohl, A., Luhar, A., and Webley, P., American Geophysical Union, Washington, DC, https://doi.org/10.1029/2012GM001244, 2012.

Ludwig, P., Pinto, J. G., Reyers, M., and Gray, S. L.: The role of anomalous SST and surface fluxes over the southeastern North Atlantic in the explosive development of windstorm Xynthia, Q. J. Roy. Meteor. Soc., 140, 1729-1741, https://doi.org/10.1002/qj.2253, 2014.

Mahoney, K. M., Jackson, D. L., Neiman, P., Hughes, M., Darby, M., Wick, G., White, A., Sukovich, E., and Cifelli, R.: Understanding the role of atmospheric rivers in heavy precipitation in the Southeast US, Mon. Weather Rev., 144, 1617-1632, https://doi.org/10.1175/MWR-D-15-0279.1, 2016.

Malguzzi, P., Grossi, G., Buzzi, A., Ranzi, R., and Buizza, R.: The 1966 "century" flood in Italy: a meteorological and hydrological revisitation, J. Geophys. Res.-Atmos., 111, 111, D24106, https://doi.org/10.1029/2006JD007111, 2006.

Munich Re: Natural Catastrophes 2014, Analyses, Assessments, Positions, TOPICS-GEO 2014, Munich, 67 p., 2015.

Neiman, P. J., Ralph, F. M., Wick, G. A., Lundquist, J. D., and Dettinger, M. D.: Meteorological characteristics and overland precipitation impacts of atmospheric rivers affecting the West Coast of North America based on eight years of SSM/I satellite observations, J. Hydrometeorol., 9, 22-47, https://doi.org/10.1175/2007JHM855.1, 2008.

Neu, U., Akperov, M. G., Bellenbaum, N., Benestad, R., Blender, R., Caballero, R., Cocozza, A., Dacre, H. F., Feng, Y., Fraedrich, K., Grieger, J., Gulev, S., Hanley, J., Hewson, T., Inatsu, M., Keay, K., Kew, S. F., Kindem, I., Leckebusch, G. C., Liberato, M. L., Lionello, P., Mokhov, I. I., Pinto, J. G., Raible, C. C., Reale, M., Rudeva, I., Schuster, M., Simmonds, I., Sinclair, M., Sprenger, M., Tilinina, N. D., Trigo, I. F., Ulbrich, S., Ulbrich, U., Wang, X. L., and Wernli, H.: IMILAST: A Community Effort to Intercompare Extratropical Cyclone Detection and Tracking Algorithms, B. Am. Meteorol. Soc., 94, 529-547, https://doi.org/10.1175/BAMS-D-11-00154.1, 2013. 
Newell, R. E. and Zhu, Y.: Tropospheric rivers: a one-year record and possible application to ice core data, Geophys. Res. Lett., 21, 113-116, https://doi.org/10.1029/93GL03113, 1994.

Pinto, J. G., Zacharias, S., Fink, A. H., Leckebusch, G. C., and Ulbrich, U.: Factors contributing to the development of extreme North Atlantic cyclones and their relationship with the NAO, Clim. Dynam., 32, 711-737, https://doi.org/10.1007/s00382008-0396-4, 2009.

Pirret, J. S. R., Knippertz, P., and Trzeciak, T. M.: Drivers for the deepening of severe European windstorms and their impacts on forecast quality, Q. J. Roy. Meteor. Soc., 143, 309-320, https://doi.org/10.1002/qj.2923, 2017.

Ralph, F. M. and Dettinger, M. D.: Storms, floods, and the science of atmospheric rivers, Eos Trans. AGU, 92, 265, https://doi.org/10.1029/2011EO320001, 2011.

Ralph, F. M., Neiman, P. J., and Wick, G. A.: Satellite and CALJET aircraft observations of atmospheric rivers over the eastern North Pacific Ocean during the winter of 1997/98, Mon. Weather Rev., 132, 1721-1745, https://doi.org/10.1175/15200493(2004)132<1721:SACAOO>2.0.CO;2, 2004.

Ramos, A. M., Trigo, R. M., Liberato, M. L. R., and Tome, R.: Daily precipitation extreme events in the Iberian Peninsula and its association with Atmospheric Rivers, J. Hydrometeorol., 16, 579-597, https://doi.org/10.1175/JHM-D-14-0103.1, 2015.

Ramos, A. M., Nieto, R., Tomé, R., Gimeno, L., Trigo, R. M., Liberato, M. L. R., and Lavers, D. A.: Atmospheric rivers moisture sources from a Lagrangian perspective, Earth Syst. Dynam., 7, 371-384, https://doi.org/10.5194/esd-7-371-2016, 2016a.

Ramos, A. M., Tomé, R., Trigo, R. M., Liberato, M. L. R., and Pinto, J. G.: Projected changes in atmospheric rivers affecting Europe in CMIP5 models, Geophys. Res. Lett., 43, 9315-9323, https://doi.org/10.1002/2016GL070634, 2016b.

Sanders, F. and Gyakum, J. R.: Synoptic-dynamic climatology of the "bomb", Mon. Weather Rev., 108, 1589-1606, https://doi.org/10.1175/15200493(1980)108<1589:SDCOT>2.0.CO;2, 1980.

Shapiro, M. A., Wernli, H., Bao, J.-W., Methven, J., Zou, X., Neiman, P. J., Donall-Grell, E., Doyle, J. D., and Holt, T.: A planetary-scale to mesoscale perspective of the life cycles of extratropical cyclones: The bridge between theory and observations, in: The life cycles of extratropical cyclones, edited by: Grønås, S. and Shapiro, M. A., 139-185, Amer. Met. Soc., Boston, USA, 1998.
Snyder, C. and Lindzen, R. S.: Quasi-geostrophic wave-CISK in an unbounded baroclinic shear, J. Atmos. Sci., 48, 78-88, 1991.

Trigo, I. F.: Climatology and interannual variability of stormtracks in the Euro-Atlantic sector: a comparison between ERA40 and NCEP/NCAR reanalyses, Clim. Dynam., 26, 127-143, https://doi.org/10.1007/s00382-005-0065-9, 2006.

Trigo, I. F., Davies, T. D., and Bigg, G. R.: Objective climatology of cyclones in the Mediterranean region, J. Climate, 12, 1685-1696, 1999.

Trigo, I. F., Bigg, G. R., and Davies, T. D.: Climatology of cyclogenesis mechanisms in the Mediterranean, Mon. Weather Rev., 130, 549-569, 2002.

Tsou, C.-H., Smith, P. J., and Pauley, P. M.: A comparision of adiabatic and diabatic forcing in an intense extratropical cyclone system, Mon. Weather Rev., 115, 763-786, https://doi.org/10.1175/15200493(1987)115<0763:ACOAAD>2.0.CO;2, 1987.

Viale, M. and Nuñez, M. N.: Climatology of winter orographic precipitation over the subtropical Central Andes and associated synoptic and regional characteristics, J. Hydrometeorol., 12, 481507, 2011.

Wernli, H., Dirren, S., Liniger, M. A., and Zillig, M.: Dynamical aspects of the life-cycle of the winter storm "Lothar" (2426 December 1999), Q. J. Roy. Meteor. Soc., 128, 405-429, https://doi.org/10.1256/003590002321042036, 2002.

Whitaker, J. S. and Davis, C. A.: Cyclogenesis in a saturated environment, J. Atmos. Sci., 51, 889-908, 1994.

Zhu, Y. and Newell, R. E.: Atmospheric rivers and bombs, Geophys. Res. Lett., 21, 1999-2002, 1994.

Zhu, Y. and Newell, R. E.: A proposed algorithm for moisture fluxes from atmospheric rivers, Mon. Weather Rev., 126, 725735, 1998. 